
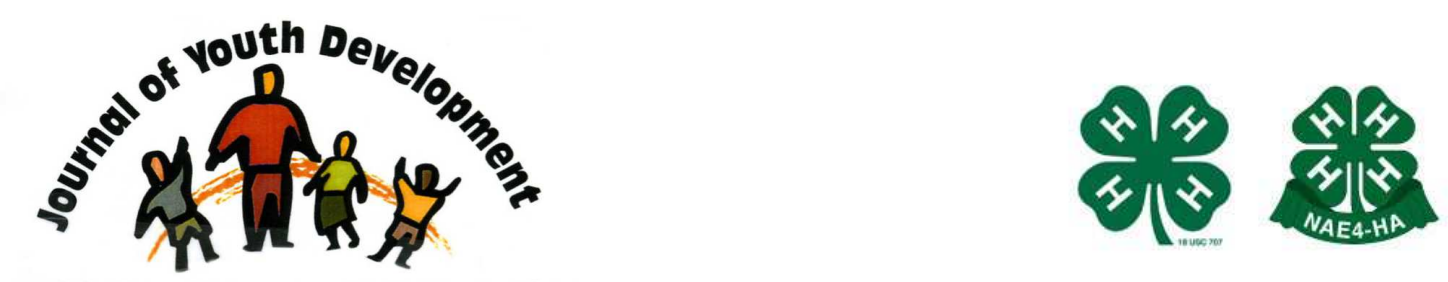

Bridging Research \& Practice

\title{
Latino Youth Participation in Community Programs
}

\author{
Linda Skogrand \\ Family, Consumer and Human Development \\ Utah State University \\ Logan, UT \\ lindas@ext.usu.edu \\ Kathleen Riggs \\ Iron County Cooperative Extension \\ Utah State University \\ Cedar City, UT \\ Stacey Huffaker \\ Family, Consumer and Human Development \\ Utah State University \\ Logan, UT
}




\title{
JOURNAL OF YOUTH DEVELOPMENT \\ bridging research and practice

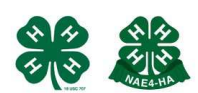

Volume 3, Number 2, Fall 2008

Article 080302RS002

\section{Latino Youth Participation in Community Programs}

\author{
Linda Skogrand, Kathleen Riggs and Stacey Huffaker \\ Utah State University
}

\begin{abstract}
Twelve Latino parents were interviewed regarding what attracted their children to community activities and ways to increase participation of Latino youth in activities. According to the parents interviewed, children participated in activities which they enjoyed, activities that made them productive and kept them out of trouble, helped them gain skills that would benefit their future, and activities that involved the entire family. Implications for programming for Latino youth are provided.
\end{abstract}

\section{Introduction}

The United States is becoming culturally more diverse with the Hispanic/Latino population currently the largest minority group in the United States (El Nasser, 2003). According to Census Data, while the United States population grew by 13\% from 1990 to 2000 the Latino population grew by $58 \%$ (Guzman, 2001). The Latino population continued to grow disproportionately after the 2000 census, increasing by 14\% from 2000 to 2004, while the non-Latino population grew by only $2 \%$ (Pew Research Center, 2005). The growth rate of Latino immigrant population in the United States has impacted many aspects of society. Both, rural and urban communities have experienced growth in Latino immigrants, with many rural communities experiencing rapid growth because of employment opportunities in food processing plants and harvesting of crops (Berry \& Kirschner, 2002). Some parts of the United States have larger Latino populations than others. For example, Latinos, especially young families, now constitute $24 \%$ of the population in western states (Berry \& Kirschner, 2002). In addition, the Latino population in the United States is younger than the population as a whole, with approximately one-third of the Latino population being under 18 years of age.

As this growth in the Latino immigrant population in the United States continues, there will be an increasing need for youth leaders and community leaders to provide culturally appropriate programming to help families and youth. Much information and programming for Latinos is not culturally relevant. Therefore, there is a need for research to be conducted within a cultural 
context (DeMaria, 2005; Doherty \& Anderson, 2004; Ooms \& Wilson, 2004; Willey \& Ebata, 2004).

One might ask: "Why is it important to address the issue of family life from the perspective of the immigrant population's culture?" There are two responses to this question. First, if there is a cultural clash between educational information provided and the values of a population, they will usually not attend educational programs (Ernst, 1990). Currently, Latino youth are underrepresented in community programs (Wimer, et al., 2006). If they do attend, they will not benefit from the information provided (Ernst, 1990) and harm may result if individuals embrace programming ideas that destroy components of their cultural heritage.

Secondly, there is evidence that relying upon one's cultural heritage, the way one's people deal with struggles, is the most effective way for people to be resilient and capable of handling difficulties (Delgado, 1998). McGoldrick and Giordano (1996) also assert that those who try to completely assimilate into the dominant culture, rather than maintaining a connection to their cultural values, are likely to have difficulties in dealing with life's problems.

In addition, there is evidence that not completely assimilating, by being bicultural and continuing to maintain one's original cultural values, contributes to positive mental health (Falicov, 1998; LaFramboise, Coleman, \& Gerton, 1993). Consequently, it is important to draw on and reinforce the existing family values that are evident in the Latino culture when including youth in community programs (DeBord \& Reguero de Atiles, 1999; Ooms \& Wilson, 2004; Powell, 1988; Vega, 1990).

Social science literature informs us about features and cultural themes of the Latino culture that are part of family life, but there is very little research data available about what makes Latino families work (McGoldrick, Preto, Hines, \& Lee, 1991; Wiley \& Ebata, 2004). We, therefore, relied primarily on descriptions of cultural themes in the literature to guide our research and interpret findings.

The concept of familism is a dominant theme in Latino culture (Falicov, 1998; Santiago-Rivera, et al., 2002). Familism refers to the close relationships that are promoted and exist among Latino family members, which includes interdependence and cooperation among family members with a willingness to sacrifice individual needs for the welfare of the group or family (Falicov, 1998; Santiago-Rivera, et al., 2002). Family affiliation is so important that parenthood is considered to be more important than partnerhood (Falicov, 1998). Intergenerational connections, such as the relationship of a parent to a child, often take precedence over the marital relationship, with the children having a higher priority than the marriage (Falicov, 1998; Penn, Hernández, \& Bermúdez, 1997). Researchers have found that familism is an enduring trait even when families become highly acculturated (Santiago-Rivera, et al., 2002). SuárezOrozco and Suárez-Orozco (1995) concluded that "family" was the most important value among both first and second generation Latino adolescents, as compared to European American adolescents who did not rate family as highly.

Personalismo, which is valuing warm, friendly, and somewhat informal, interpersonal relationships, is also an important value in Latino culture. This focus on warm and positive interpersonal relationships is especially important among family members. Having a positive relationship with a person may be more important than the task at hand (Santiago-Rivera, et al., 2002). 
The research literature about developmental assets and the effects of these assets on positive youth development is also relevant to the topic of community programs for youth.

Developmental assets is a strengths-based framework designed by the Search Institute that focuses on building 40 assets that help youth to be successful across family, neighborhood, and school settings (Leffert, Benson, Scales, Sharma, Drake, \& Blyth, 1998). Questionnaires have been given to youth in grades 6 through 12 to measure the 40 assets and thriving indicators. In one study, the survey was given across ethnic groups. For Latino and European American youth, the asset, "time in youth programs," contributed to the variance in five of the seven thriving indicators (school success, leadership, physical health, helping others, and overcoming adversity). Time in youth programs, planning and decision making, cultural competence, and self-esteem contributed to the thriving index for these groups. For Latino youth, assets that were especially important related to family support, responsibility, interpersonal competence, and the presence of a caring community or neighborhood (Scales, Benson, Leffert, \& Blyth, 2000). Therefore, it is important to provide programming to Latino youth that provides opportunities to develop these assets.

In summary, it is important that we recognize the need to create and attract the growing Latino youth population to community programming. Youth programming can be greatly beneficial in helping Latino youth succeed in school and the community. It is also important that programming be provided within the context and strengths of Latino culture. This is necessary in order to attract and retain youth, as well as providing youth with a positive attitude about their cultural heritage. This study addresses why Latino youth are currently participating in community programming and what additional things need to be done to increase participation of these youth in community programming.

\section{Methods}

We conducted an exploratory, qualitative study asking 12 Latino parents what was attracting their Latino youth to programs in which they were involved, and what additional things would make programming attractive to them and their children. Those selected for interviews were parents of Latino youth ages 10 to 14 years. Half of the parents already had one or more of their children involved in Extension youth programs, while the other half did not have their children involved in Extension programs, but may have been involved in other community youth activities.

Open-ended questions were asked about why children were participating in programs and what could be done to attract more Latino youth to such programs. The interviews were conducted in Spanish and took place somewhere that was convenient for the parent. The interviews were tape-recorded and translated and transcribed. The data was analyzed by looking for themes that addressed the research questions.

The study was conducted in a rural community in a western state. Although we were interested in interviewing parents, we found that mothers were more available than fathers. Eleven of the participants were mothers and one was a father. The median household income of the participants was $\$ 25,000$ per year with most husbands in the household being involved in labor and construction. The Latino parent had from two to five children, ranging in age from 5 months to 19 years. 


\section{Findings}

The parents who participated in this study provided information about what attracted their children to activities in which they were currently participating. These parents also provided suggestions for ways to increase participation of all Latino youth.

\section{Reasons for Current Participation}

Four themes emerged about parents' criteria for their children's activities. Parents wanted their children to choose activities that they enjoyed, were productive and kept them out of trouble, helped them to gain skills which would benefit their future, and activities that would involve the entire family.

Their children's happiness was most important to parents and parents wanted their children to choose activities which they enjoyed. A parent stated, "We have kids and we try to make them happy. In reality, they are going to [choose] what they need, or what they want to learn." Activities were viewed as beneficial when their children continued to be interested in them

The important thing is that they like it and they participate and they feel good. It won't do any good if I say I want them to do this. If they don't like it, they aren't going to feel good and they aren't going to do it.

Some parents drew upon their children's interest in activities to motivate them to succeed in school. One parent would permit her son to participate in sports if he did not fall behind in his studies.

According to the parents who were interviewed, they wanted their children to participate in meaningful activities and to avoid idleness. Parents supported sports activities where their children could spend time doing something good. Rather than having their children participating in unproductive activities like watching television or playing video games, parents wanted their children to stay busy and, "they did not have time to put bad things into their heads."

Productive activities also included activities that helped children acquire academic and social skills which gave them confidence and competence that would be beneficial for their future. Because many Latino children needed help with school work, parents who knew little or no English themselves sought out community programs for academic assistance for their children. One parent was especially appreciative of a program that helped her daughter develop confidence in school because her daughter improved her reading skills.

Parents were also appreciative of programs that helped their children practice social skills. One parent who was concerned about her children's social skills reported that her children had learned to interact with other people and be more talkative through participation in community programs. Another parent said community programs had helped her son learn to share and get along with his younger siblings and other children.

Parents enjoyed having their children participate in activities that involved the entire family. Activities that involved family members going in different directions were not helpful for families who were making efforts to create family time. One parent talked about a youth activity that involved a weekly family time by saying, "We learned as a family. At least once a week we could all be together. It has helped us a lot to share a little more time." 


\section{Ways to Increase Participation}

We asked participants how we could increase Latino youth participation in programming. Participants suggested programs should advertise and provide programming in Spanish, extend personal invitations, and welcome all people regardless of their ethnicity.

Participants indicated they would be better informed about and more interested in programs if they were advertised in Spanish:

If [fliers] are in Spanish they are going to attract more attention, because I am going to participate. If it's in English, I don't pay attention. If it's in English it doesn't catch my attention. It's easier in Spanish.

Parents indicated that advertisements should be large enough to be noticed and should be in places Latinos frequent, such as schools, libraries, stores such as Wal-Mart, laundromats, factories where many Latino's work, parks, and Latino-owned businesses. Announcements could be broadcast on a Spanish radio station because, according to one parent, not many people have access to television in Spanish.

In addition to advertising in Spanish, parents suggested that community leaders should offer programming in Spanish:

\section{Many Latinos don't speak the language well or sometimes we don't understand everything so it would be very important that someone speak Spanish to be able to express everything that we want.}

It was also important to personally contact Latinos so they know that they are welcome to participate in community programs. Participants described how they sometimes attended public events and, because of their ethnicity, they felt not welcome. One parent said, "You have to invite them, you have to tell them that there is a program that helps them." Parents made it clear that it was best to invite Latinos through a phone call or a personal visit. This personal invitation is how they would be informed about the program and also know that they were welcome. Furthermore, parents wanted reminders about their children's activities through a personal telephone call or a note sent home with their children. Because Latinos usually learned about programs through involved Latino friends, parents said that if community leaders gave them information about programs, they would pass the word on to their friends.

Parents also expressed desire to be involved in their children's activities by saying, "You can't just send them and leave them there, but [you need to] be there, knowing what they are doing and how it is going to serve them." Participants also indicated that community leaders can encourage parents to be involved in their children's activities by inviting them. One parent stated, "Just let us know that there is this type of activity and we can come, invite us, invite the children." Parents will attend activities when they know about them. Although many parents went to their children's activities, others could not because of other commitments such as work. One parent said, "I think that for me to participate my time is too limited. I almost never have a day off." When parents worked and were unavailable to bring children to an event, it was important that transportation be provided for their children.

Most parents seemed to think that any location for activities would be fine as long as the place was appropriate, they were not imposing on someone else, and there was adequate space that all could be seated comfortably. One parent said, "It can be at the park, at a lake, at home, it 
can be sidewalk in the street. It can be far or it can be close, no problem. If I know the people I feel more comfortable." When one parent was asked how to help the Latino community become more involved, she conversed openly about the discrimination that she had encountered by saying:

Yes, you feel it, when they are discriminating against you. It's like you as an American go to a party and all of the Hispanics are in one corner talking and you alone at a table, what are you going to think. What do you feel?

Having experienced discrimination themselves, parents wanted to include all people, and suggested activities in which people of all ethnicities could share time together. One way to involve parents and show respect for their culture is to encourage them to share their cultural knowledge and skills. One parent suggested that she and other mothers could help by making food to sell to raise money for her children's activities. She was very enthusiastic about her ideas and willing to help out in whatever way she could.

\section{Conclusions and Implications}

Results from this study bring insight into how community leaders can direct their recruitment and programming in ways that are culturally appropriate and responsive to the needs of the Latino population. The importance that Latino parents placed on their children's activities supported literature about the Latino culture that states that intergenerational connections, such as the relationship of a parent to a child, take high precedence in the family (Falicov, 1998; Penn, Hernández, \& Bermúdez, 1997).

Many parents wanted their children to learn skills and be able to participate in activities that could involve their family. This supports other research that states that familism is an enduring trait even when families become highly acculturated (Santiago-Riviera, Arredondo, and Gaollardo-Cooper, 2002). This closeness among family members can be viewed as a source of strength in Latino families because it can be a resource in providing financial or social support in times of crises (Santiago-Rivera, et al., 2002). Rather than trying to replace the family, community leaders should offer programming that builds upon Latino's family values and involves family members. Programming that does not seem to be family oriented may not be attractive to the Latino population because they do not want their children involved in activities that may supersede the family connections. Community program leaders also need to analyze the values that are transmitted by their programs to see if they are in line with Latino family values.

The lack of information and the lack of communication between the Latino and majority population was identified as an enormous barrier to Latino participation in community programs. Many Latinos do not understand English very well and lack the social networks that would help them to hear about programs to help their children. Even if they had heard about programs, some did not participate because they had not personally received the information.

Personalismo, which is valuing warm, friendly, and somewhat informal, interpersonal relationships, is important in Latino culture (Santiago-Rivera, et al., 2002). Having a positive relationship with a person may be more important than the task at hand (Santiago-Rivera, et al., 2002) and this may be true in fostering relationships that encourage the Latino community to participate in community programs. If they lacked the personal connection with people in the community, they may have felt isolated and discriminated against. It is imperative that 
community leaders welcome, include, and build relationships with all people in their programs. They should do so without making them feel like they are being patronized and should focus on the personal relationship and the needs of the individual. One way to help parents feel welcome is to invite them to share their knowledge and skills to help out in whatever way they can. When people feel needed they are more likely to feel included and welcome.

It is important that community leaders meet the needs of the Latino community by: (a) advertising and programming in the Spanish language (b) offering personal invitations (c) helping them feel welcome through building personal relationships and helping them to feel needed by drawing upon their strengths and talents. If Latinos are informed, invited, and included, they will come. As one parent said, "If you invite the Latino community then, yes, we participate."

\section{References}

Berry, E.H., \& Kirschner, A. (2002). The changing face of the rural west. Western Rural Development Center Information Brief, Issue 1.

DeBord, K.B., \& Reguero de Atiles, J.T. (1999). Latino parents: Unique preferences for learning about parenting. The Forum for Family and Consumer Issues, 4. Retrieved January 20, 2006, from: http://www.ces.ncsu.edu/depts/fcs/pub/1999/latino.html

Delgado, M. (1998). Social services in Latino communities: Research and strategies. New York: Haworth Press.

DeMaria, R.M. (2005). Distressed couples and marriage education. Family Relations, 54, 242253.

Doherty, W.J., \& Anderson, J.R. (2004). Community marriage initiatives. Family Relations, 53, 425-432.

El Nasser, H. (2003, June 18). 39 million make Hispanics largest U.S. minority group. USA Today. Retrieved August 10, 2004 from http://www.usatoday.com/news/nation/census/2002-06-18-Census htm

Ernst, L. (1990). Value differences in families of differing socioeconomic status: Implications for family education. Family Perspective, 24, 401-410.

Falicov, C.J. (1998). Latino families in therapy. New York: Guildford Press.

Guzman, B. (2001). The Hispanic population: Census 2000 brief. United States Census 2000. Washington, D.C.: U.S. Department of Commerce.

LaFramboise, T., Coleman, H.L., \& Gerton, J. (1993). Psychological impact of biculturalism: Evidence and theory. Psychological Bulletin, 114, 395-412.

Leffert, N., Benson, P.L., Scales, P.C., Sharma, A.R., Drake, D.R., \& Blyth, D.A. (1998). Developmental assets: Measurement and prediction of risk behaviors among adolescents. Applied Developmental Science, 2, 209. 
McGoldrick, M., \& Giordano, J. (1996). Overview: Ethnicity and family therapy. In M. McGoldrick, J.Giordano, \& J.K. Pearce (Eds.), Ethnicity and family therapy, (2 ${ }^{\text {nd }}$ ed.) New York: Guilford Press.

McGoldrick, M., Preto, N.G., Hines, P.M., \& Lee, E. (1991). Ethnicity and family therapy. In A. Gurman \& D. Kniskern (Eds.), Handbook of family therapy, Vol. 2, (pp. 546-582). New York: Brunner/Mazel.

Ooms, T., \& Wilson, P. (2004). The challenge of offering relationship and marriage education to low-income populations. Family Relations, 53, 440-447.

Penn, C.D., Hernández, S.L., \& Bermúdez, J.M. (1997). Using a cross-cultural perspective to understand infidelity in couples therapy. The American Journal of Family Therapy, 25, 169-185.

Pew Research Center (2005). Hispanics: A people in motion. Retrieved January 28, 2006, from http://www.pewresearch.org

Powell, D.R. (Ed.). (1988). Parent education as early childhood intervention: Emerging directions in theory, research, and practice. Norwood, NJ: Ablex Publishing.

Santiago-Rivera, A.L., Arredondo, P., \& Gallordo-Cooper, M. (2002). Counseling Latinos and la familia: A practical guide. Thousand Oaks, CA: Sage Publications.

Scales, P.C., Benson, P.L, Leffert, N., Blyth, D.A. (2000). Contribution of Developmental Assets to the Prediction of Thriving Among Adolescents. Applied Developmental Science, 4, 27.

Suárez-Orozco, C., \& Suárez-Orozco, M. (1995). Transformations: Immigration, family life, and achievement motivation among Latino adolescents. Stanford, CA: Stanford University Press.

Vega, W.A. (1990). Hispanic families in the 1980s: A decade of research. Journal of Marriage and the Family, 52, 1015-1024.

Wiley, A.R., \& Ebata, A. (2004). Reaching American families: Making diversity real in family life education. Family Relations, 53, 273-281.

Wimer, C., Bouffard, S.M., Caronongan, P., Dearing, E., Simpkins, S., Little, P.M.D., \& Weiss, $\mathrm{H} .$, (2006). What are kids getting into these days? Demographic differences in youth out-of school time participation. Harvard Family Research Project. Cambridge, MA. Retrieved May 12, 2006 from http://www.gse.harvard.edu/hfrp/projects/afterschool/resources/demographic.html

(C) Copyright of Journal of Youth Development Bridging Research and Practice. Content may not be copied or emailed to multiple sites or posted to a listserv without copyright holder's express written permission. Contact Editor at: patricia.dawson@oregonstate.edu for details. However, users may print, download or email articles for individual use.

ISSN 2325-4009 (Print); ISSN 2325-4017 (Online) 